\title{
FONTES DE CRESCIMENTO DE MANDIOCA NA MICRORREGIÃO DO GUAMÁ, ESTADO DO PARÁ, NO PERÍODO 1990-2011
}

\author{
Francisco Carlos Almeida de Souza ${ }^{1}$; José Darlon Nascimento Alves ${ }^{2}$; Antonia Moraes \\ Mota $^{3}$; Marcos Antônio Souza dos Santos ${ }^{4}$. \\ ${ }^{1}$ Graduando do curso de Agronomia do Instituto Federal do Pará. Castanhal, Pará, Brasil. \\ agrocarlosifpa@hotmail.com \\ ${ }^{2}$ Graduando do curso de Agronomia da Universidade Federal Rural da Amazônia (UFRA). \\ Capitão Poço, Pará, Brasil. jose.darllon@ hotmail.com \\ ${ }^{3}$ Graduanda do Curso de Agronomia da UFRA. Capitão Poço, Pará, Brasil. \\ joaotonheiro@gmail.com \\ ${ }^{4}$ Professor de Economia Rural da Universidade Federal Rural da Amazônia (UFRA). \\ marcos.santos@ufra.edu.br.
}

\begin{abstract}
RESUMO: O trabalho avalia a evolução e identifica as fontes de crescimento da produção de mandioca na microrregião do Guamá no período 1990-2011. Os dados utilizados foram obtidos a partir do Instituto Brasileiro de Geografia e Estatística (IBGE). Foi empregado o método shift-share que permite decompor a taxa de crescimento da produção nos efeitos área e rendimento. No período de 1990 a 2009 a produção da mandioca da microrregião do Guamá, evoluiu a uma taxa de $3,7 \%$ ao ano. Destaca-se que o principal fator responsável por este crescimento foi o efeito-área, pois a área colhida cresceu a uma taxa de 1,38\% ao ano. A taxa de crescimento da produtividade (efeito-rendimento) cresceu a uma taxa de $2,3 \%$, sendo positiva, entretanto, se mostrou inferior ao crescimento da produção. Este resultado aponta para a necessidade de ampliar o nível tecnológico dos sistemas de produção de mandioca na microrregião do Guamá, visando incrementar a produtividade das lavouras.
\end{abstract}

PALAVRAS-CHAVE: economia, formação de preços, comercialização.

\section{SOURCES OF GROWTH IN YUCCA MICROREGION OF GUAMÁ, PARÁ STATE, IN THE PERIOD 1990-2011}

\begin{abstract}
The work evaluates the evolution and identifies the sources of growth of cassava production in the microregion of Guamá in the period 1990-2011. The data used were obtained from the Brazilian Institute of Geography and Statistics (IBGE). Method was used shift-share decomposition that allows the growth rate of production in the area and yield effects. In the period 1990-2009 the production of cassava in the microregion of Guamá, evolved at a rate of $3.7 \%$ per year. It is noteworthy that the main factor responsible for this increase was the effect-area because the harvested area grew at a rate of $1.38 \%$ per annum. The rate of productivity growth (effect-income) grew at a rate of $2.3 \%$, being positive, however, was inferior to output growth. This result points to the need to expand the technological level of cassava production systems in the micro Guamá, thus increasing crop productivity.
\end{abstract}

KEY-WORDS: economics, pricing, marketing. 
A mandioca de mesa (Manihot esculenta Crantz.) pode ser considerada como um produto hortícola amplamente consumido em todo o Brasil. Nos grandes centros urbanos é comercializada in natura, minimamente processada ou processada na forma de pré-cozidos, congelados e massas. Esse mercado está em expansão, tanto para o abastecimento interno como para exportação, todavia devido à deterioração pós-colheita, exige abastecimento contínuo (AGUIAR et al., 2011).

Apesar de apresentar alto potencial produtivo, alcançando em alguns estudos valores superiores a $100 \mathrm{t} \quad \mathrm{ha}^{-1}$, a produtividade nacional é baixa $\left(14,26 \mathrm{t} \mathrm{ha}^{-1}\right)$ (SILVA et al., 2012).

A microrregião do Guamá abrange os municípios: Aurora do Pará, Cachoeira do Piriá, Capitão Poço, Garrafão do Norte, Ipixuna do Pará, Irituia, Mãe do rio, Nova Esperança do Piriá, Ourém, Santa Luzia do Pará, São domingos do Capim, São Miguel do Guamá e Viseu, todos no estado do Pará (IBGE, 2013).

Essa microrregião está inserida na mesorregião do Nordeste Paraense a qual Modesto Júnior et al. (2011) caracteriza num contexto produtivo agropecuário como principais produtores, os estabelecimentos familiares que na sua maioria se dedicam quase que exclusivamente a exploração de culturas alimentares, como milho (Zea mays L.), feijão (Phaseolus vulgaris L.) e mandioca (Manihot esculenta Crantz) que apresentam a maior expressão sócioeconômica da região.

Este trabalho tem como objetivo analisar o comportamento das variáveis: produção, área colhida e produtividade da mandioca na microrregião do Guamá no período 1990-2011.

Os dados utilizados foram séries temporais de área colhida, produção e produtividade da cultura da mandioca na microrregião do Guamá, cobrindo o período de 1990 a 2011, disponibilizados pelo Instituto Brasileiro de Geografia e Estatística (IBGE, 2013).

Para quantificar as fontes de crescimento da produção foi empregado o método shift-share. Segundo Mesquita (1998) este método tem sido amplamente utilizado no Brasil na avaliação da ocorrência de mudança tecnológica no setor agrícola, visando determinar quanto do aumento da produção pode ser atribuído ao incremento da área colhida (efeito-área) e as melhorias no rendimento por hectare (efeito-rendimento). A pressuposição implícita é de que essas melhorias decorrem, principalmente, de inovações tecnológicas introduzidas no processo de produção.

Para maiores detalhes sobre a descrição do modelo matemático e dos 
procedimentos analíticos recomenda-se a consulta aos trabalhos de Homma (1981), Santana (1988), Filgueiras (2002) e Santos et al. (2005) que utilizaram o método shiftshare em vários estudos sobre fontes de crescimento da agricultura na Amazônia.

Em 2011, segundo dados obtidos pelo IBGE, a área colhida da mandioca na microrregião do Guamá foi da ordem de 49.330 hectares o que proporcionou uma produção de 803.641 toneladas, correspondendo a uma produtividade média de $17.329 \mathrm{~kg} \mathrm{ha}^{-1}$ (Figura 1). Ainda na Figura 1 é possível serem observadas as oscilações de área colhida, quantidade produzida e produtividade que aconteceram no decorrer dos anos compreendidos entre 1990-2011, na qual é perceptível que o ano de 1992 obteve os menores valores para as variáveis analisadas. No ano de 2006 ocorreu a maior quantidade produzida e maior área colhida, no entanto, não apresentou o melhor rendimento.

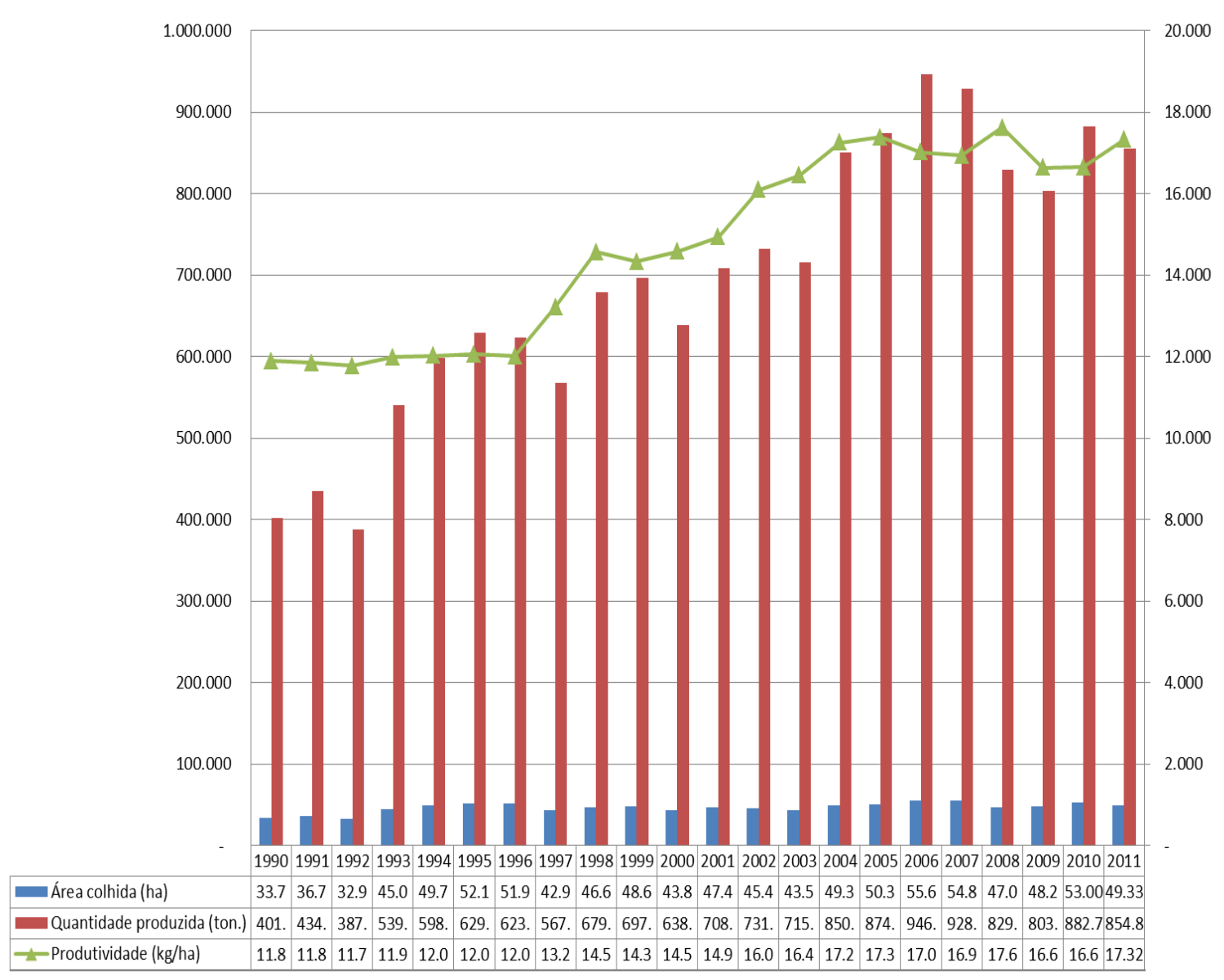

Figura 1. Evolução da área colhida, produção e produtividade da cultura do milho na microrregião do Guamá no período 1997-2010. 
No que diz respeito ao rendimento houve ganho no período avaliado, porém com leves oscilações no decorrer dos anos. Esta variável está condicionada a forma e manejo dos agricultores e relacionando com trabalhos realizados no Estado do Pará, como Modesto Júnior et al. (2011) que alcançaram produtividade média de $25.560 \mathrm{~kg} \mathrm{ha}{ }^{-1}$, utilizando práticas comumente relatadas na agricultura familiar, como cultivos em leira, para diminuir a perda de raiz por encharcamento. É visível a diferença a qual o presente trabalho aponta produtividade de $17.329 \mathrm{~kg} \mathrm{ha}^{-1}$ para a microrregião do Guamá.

No período 1990-2011 a taxa de crescimento da produção de mandioca na microrregião do Guamá foi de 3,7\% ao ano. Esse padrão de crescimento foi sustentado, principalmente, pela expansão da área colhida (efeito-área) que cresceu a uma taxa de $1,38 \%$ ao ano.

Constatou-se ganhos de produtividade (efeito-rendimento) nesse período, pois a taxa de crescimento foi de 2,3\% ao ano. Segundo o IBGE (2013), os municípios que apresentaram maiores produtividades foram: Aurora do Pará (17.994 $\mathrm{kg} \mathrm{ha}^{-1}$ ), Ipixuna do Pará (17520 kg ha $\left.{ }^{-1}\right)$, Mãe do Rio (15418 kg ha ${ }^{-1}$ ) e Capitão Poço (15090 $\left.\mathrm{kg} \mathrm{ha}^{-1}\right)$.

Observa-se que nos últimos anos está havendo uma tendência de crescimento na produtividade, sendo o valor mais alto alcançado em 2008. Esse comportamento pode estar associado aumento do uso de tecnologias e manejo das novas áreas implantadas.

Analisando os a Taxa Geométrica de Crescimento (TGC) observa-se diminuição ou leve crescimento nos municípios da microrregião do Guamá, em relação às variáveis produção e área colhida, com exceção do município de Garrafão do Norte que obteve taxa zero de crescimento (Tabela 1).

Quanto à variável produtividade observa-se que apenas quatro municípios exibiram taxas de crescimento negativas (Irituia, São Domingos do Capim, São Miguel do Guamá e Viseu). Nos demais municípios o efeito-rendimento foi positivo, sinalizando para ganhos de produtividade no período analisado.

No período analisado o crescimento da produção foi de $3,78 \%$ ao ano. Apesar de se notar ganhos de produtividade há necessidade de se ampliar o conteúdo tecnológico dos sistemas de produção da mandioca na microrregião do Guamá.

Utilização de práticas no que se refere à utilização de manivas-sementes de qualidade, espaçamento adequado e controle de plantas invasoras podem contribuir para elevar o rendimento desta cultura. 
A adoção de inovações tecnológicas combinada com outros fatores como crédito rural e assistência técnica, pode exercer papel importante no sentido de incrementar a produção e a produtividade da cultura.

Tabela 1. Taxas geométricas de crescimento por município componente da microrregião do Guamá no período de 1998-2011.

\begin{tabular}{|c|c|c|c|}
\hline \multirow[b]{2}{*}{ Municípios } & \multicolumn{3}{|c|}{ Taxas Geométricas de Crescimento (\% ao ano) } \\
\hline & Produção & $\begin{array}{l}\text { Área colhida } \\
\text { (efeito-área) }\end{array}$ & $\begin{array}{c}\text { Produtividade } \\
\text { (efeito-rendimento) }\end{array}$ \\
\hline Aurora do Pará & $-3,20$ & $-3,31$ & 9,40 \\
\hline Cachoeira do Piriá & $-3,68$ & $-4,84$ & 1,26 \\
\hline Capitão Poço & $-2,06$ & $-1,81$ & 0,17 \\
\hline Garrafão do Norte & 0,00 & 0,00 & 3,19 \\
\hline Ipixuna do Pará & $-0,01$ & $-0,01$ & 14,78 \\
\hline Irituia & 0,03 & 0,03 & $-2,31$ \\
\hline Mãe do Rio & 0,01 & 0,01 & 6,92 \\
\hline Nova Esperança do Piriá & 0,01 & 0,01 & 1,46 \\
\hline Ourém & $-0,03$ & $-0,01$ & 2,18 \\
\hline Santa Luzia do Pará & 0,01 & 0,01 & 4,84 \\
\hline São Dom. do Capim & 0,05 & 0,03 & $-2,13$ \\
\hline São Miguel do Guamá & 0,10 & 0,06 & $-2,44$ \\
\hline Viseu & 0,02 & $-0,01$ & $-0,30$ \\
\hline
\end{tabular}

Fonte: Adaptado de IBGE (2013).

\section{REFERÊNCIAS}

AGUIAR, E. B. et al. Efeito da densidade populacional e época de colheita na produção de raízes de mandioca de mesa. Bragantia. v.70, n. 3. Campinas, 2011.

FILGUEIRAS, G. C. Crescimento agrícola no Estado do Pará e a ação de políticas públicas: avaliação pelo método shift-share. Belém - UNAMA
(Dissertação - Mestrado em Economia), 2002. 156p.

HOMMA, A. K. O. Fontes de crescimento da agricultura paraense, 1970/80. Belém: EMBRAPA. CPATU, 1981 (Boletim de Pesquisa, 27).

INSTITUTO BRASILEIRO DE GEOGRAFIA E ESTATÍSTICA. Banco de dados. Disponível em:< 
http://www.sidra.ibge.gov.br>.Acesso em: 10 de abril de 2013.

MESQUITA, T. C. Estudos de economia agrícola. Sobral: Edições UVA, 1998. 168 p. MODESTO JÚNIOR, M. S.; ALVES, R. N. B.; SILVA, E. S. A. Produtividade de mandioca cultivada por agricultores familiares na região do Lagos, município de Tracuateua, estado do Pará. Amazônia: Ciência \& Desenvolvimento, Belém, v.6, n.12, 2011.

NETO, A. N. COELHO, P. J. MOREIRA, I. R. O. ANÁLISE GRÁFICA E TAXA DE CRESCIMENTO. Informações Econômicas, SP, v.23, n.10, out. 1993.

SANTANA, A. C. Crescimento e estrutura da produção agrícola na Amazônia. Boletim da FCAP, Belém, n.17, 1988, p.57-78.

SANTOS, D. V. et al. Manejo de plantas daninhas na cultura da mandioca. Planta daninha v.30, n.4, 2012.

SANTOS, M. A. S; FILGUEIRAS, G. C; ARAÚJO, M. S. P. Avaliação das fontes de crescimento da dendeicultura no estado do Pará no período 1990-2003. In: Anais do XLIII Congresso Brasileiro de Economia e Sociologia Brasileiro de Economia e Sociologia Rural. SOBER/PENSA-USP, 2005. 1 CD-ROM. 